\title{
Análisis de la sentencia C-355 de 2006 de la Corte Constitucional sobre la liberalización del aborto en Colombia: argumentos iusfilosóficos que sustentan el debate en el marco de la perspectiva de Habermas sobre el rol de la religión en la esfera pública en diálogo con Ronald Dworkin *
}

\author{
Analysis of Decision C-355 of 2006 of the Constitutional Court \\ of Colombia regarding the liberalization of abortion in Colombia: \\ Jusphilosophical arguments underlying the debate within Habermas perspective on the \\ role of religion in the public sphere with reference to Ronald Dworkin. \\ Análise da sentença c-355 do 2006 da Corte Constitucional sobre \\ a liberalização do aborto na Colômbia: argumentos iusfilosóficos que sustentam o \\ debate no marco da perspectiva de Habermas sobre o rol da religião na esfera pública em \\ diálogo com Ronald Dworkin
}

\author{
JAVIER AGUIRRE ROMÁN** \\ AlONSO Silva ROJAS ${ }^{* * *}$ \\ ANA PATRICIA PABÓN MANTILla
}

FECHA DE RECEPCIÓN: 29 DE SEPTIEMBRE DE 2014. FECHA DE ACEPTACIÓN: 20 DE ABRIL DE 2015

Doi: dx.doi.org/10.12804/esj17.02.2015.04

* El presente texto es resultado del proyecto de investigación titulado Análisis de la propuesta de Jürgen Habermas acerca del rol de la religión en la esfera pública. Tres casos de la jurisprudencia de la corte constitucional de Colombia. Este proyecto es adelantado por el grupo de investigación Politeia de la Escuela de Filosofía de la Universidad Industrial de Santander, y es financiado por la Vicerrectoría de Investigación y Extensión (VIE) de la misma universidad. El código del proyecto, el cual fue iniciado en diciembre de 2013, es 1376.

** Doctor y magíster en Filosofía, State University of New York. Profesor Asociado de la Escuela de Filosofía de la Universidad Industrial de Santander UIS. Miembro del grupo de investigación Politeia. Correo electrónico: jaguirre@uis.edu.co

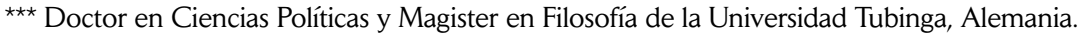
Profesor Titular de la Universidad Industrial de Santander UIS. Director del grupo de investigación Politeia. Correo electrónico: asilva@uis.edu.co

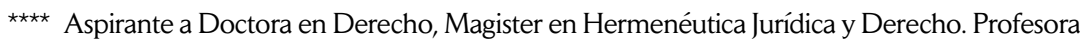
Asociada de la Facultad de Derecho de la Universidad Autónoma de Bucaramanga UNAB, vinculada al grupo de investigación Politeia. Correo electrónico: apabon742@unab.edu.co 
Para citar este artículo: Aguirre Román, J., Silva Rojas, A., E Pabón Mantilla, A. (2015). Análisis de la sentencia C-355 del 2006 de la Corte Constitucional sobre la liberalización del aborto en Colombia: argumentos iusfilosóficos que sustentan el debate en el marco de la perspectiva de Habermas sobre el rol de la religión en la esfera pública en Diálogo con Ronald Dworkin. Estudios Socio-Jurídicos, 17(2), 167-197. Doi: dx.doi. org/10.12804/esj 17.02.2015.04

\title{
RESUMEN
}

El presente texto constituye un artículo de reflexión producto de la investigación sobre la postura que ha adoptado la Corte Constitucional de Colombia en relación con los argumentos religiosos en acciones de inconstitucionalidad en casos controvertidos. Para analizar dicho problema, se tiene como referente teórico la propuesta de Jürgen Habermas sobre el rol de la religión en la esfera pública y elementos de su propuesta sobre la función del Tribunal Constitucional. En este producto de investigación se reflexionará sobre los argumentos propuestos en el debate constitucional de la Corte Constitucional de Colombia, a propósito de la Sentencia C-355 de 2006, que liberaliza la interrupción voluntaria del embarazo en algunas circunstancias, con el fin de evaluar la coherencia de dichos argumentos desde la perspectiva liberal y del papel de los preceptos religiosos en dicho debate. Para llevar a cabo un mejor desarrollo del tema, la perspectiva de Habermas será complementada con la visión de Ronald Dworkin.

Palabras clave: Estado constitucional, democracia deliberativa, esfera pública, Corte Constitucional, aborto.

\begin{abstract}
This text is a product of a research project focused on the perspective that the Constitutional Court of Colombia has taken with regard to the religious arguments presented in constitutional legal actions. The theoretical framework used to develop the analysis is Habermas' account of the role of religion in the public sphere as well as his ideas on the role of the constitutional tribunals. In this particular text the case selected was the case law C-355 of 2006. In this case, the Court decriminalize, in some cases, the voluntary interruption of pregnancy. In order to develop a full analysis of such a controversial issue, Habermas' perspective is complemented with Dworkin's own view on the topic.
\end{abstract}

Key words: Constitutional state, deliberative democracy, public sphere, Constitutional court, abortion.

\section{RESUMO}

O presente texto constitui um artigo de reflexão produto da pesquisa sobre a postura que tem adotado a Corte Constitucional da Colômbia em relação com os argumentos religiosos em ações de inconstitucionalidade em casos controvertidos. Para analisar dito problema, tem-se como referente teórico a proposta de Jürgen Habermas sobre o rol da religião na esfera pública e elementos de sua proposta sobre a função do Tribunal Constitucional. Neste produto de pesquisa se reflexionará sobre os argumentos propostos no debate constitucional ao interior da Corte Constitucional da Colômbia, a propósito da Sentença C-355 de 2006 que liberaliza a interrupção voluntária da gravidez em algumas circunstâncias, com o fim de avaliar a coerência de ditos argumentos com a perspectiva liberal e o papel dos argumentos religiosos em dito debate. Para levar a cabo um melhor desenvolvimento do tema, a perspectiva de Habermas será complementada com a visão de R. Dworkin.

Palavras- chave: Estado constitucional, a democracia deliberativa, esfera pública, do tribunal constitucional, aborto. 


\section{Introducción}

El concepto de validez de las normas jurídicas ha dado un importante giro en el trascurso de los últimos siglos. De una concepción netamente formalista, según la cual las normas eran válidas si el legislador las había promulgado de acuerdo a las regulaciones establecidas para ello, se pasó a una noción "material" en la que se incluye la necesidad de estudiar, si además de respetar el procedimiento legal, las normas jurídicas son coherentes con ciertos principios fundamentales y materiales consagrados explícita o implícitamente en las constituciones modernas.

A partir de la segunda mitad del siglo XX, se ha ido haciendo efectiva una comprensión del Derecho y del Estado, coherente con la obligatoriedad de garantizar, de manera real y efectiva, los derechos consagrados en las Constituciones. Norma fundamental que actúa como referente para juzgar la validez de las demás normas jurídicas. Este desarrollo puede ser entendido de la siguiente manera:

Después de la Segunda Guerra Mundial y con el surgimiento de los derechos fundamentales, la función judicial adquiere dimensiones especiales en la consolidación y protección de los derechos fundamentales. Son analizados e interpretados en su validez no solo formalmente, sino también en su dimensión sustancial -esfera de lo decidible y de lo indecidible para el legislador-. Surgen como límites a las actuaciones de los poderes públicos, fungen como control mayoritario a los abusos del poder, legitiman o deslegitiman los estados de derecho (Durango, 2007, p. 92).

En Colombia -en este marco de comprensión de la relación entre la ley y la constitución, entre el poder legislativo y el poder de control constitucional y entre la opinión de las mayorías y el poder de garantía constitucional eficaz de los derechos fundamentales y humanos- la Constitución de 1991 representó la instauración de un Estado constitucional, en el cual se plasmaron unos derechos fundamentales que constituyen criterios definitorios de lo correcto o incorrecto desde el punto de vista jurídico. Este cambio paradigmático se explica en "(...) la existencia de ciertos contenidos (los derechos fundamentales) que limitan o condicionan la producción, la interpretación y la aplicación del Derecho" (Atienza, 2005, p. 25). 
Lo anterior conlleva la idea de la necesidad del sometimiento de todo poder del Estado, en la actividad de sus ramas legislativa, ejecutiva y judicial, a la razón expresada en la Constitución. Es por ello que, en nuestro caso, la Corte Constitucional ha adquirido un valor decisivo en relación con la determinación de todas las líneas en las cuales se desarrollan la vida social, política, económica y cultural del país. Esto explica por qué es precisamente en el seno de su actividad interpretativa en donde se concentran, de manera privilegiada, los más álgidos debates en torno a los asuntos valorados como significativos en términos sociales y políticos.

La pregunta que constituyó el eje de esta investigación gira, precisamente, en torno a la actividad interpretativa de la Corte Constitucional colombiana, "expresión de la razón pública», en asuntos que generan controversia, y al tipo de argumentos que en ella prevalecen. La Corte Constitucional, como suprema intérprete de la Constitución, adopta decisiones que pueden comprenderse desde una determinada perspectiva teórico política o filosófica. En ese sentido ya anotaba Dworkin sobre el papel del juez:

Los jueces como todos los funcionarios políticos, están sometidos a la doctrina de la responsabilidad política, que en su forma más general, enuncia que los funcionarios políticos no deben tomar otras decisiones políticas que las que puedan justificar dentro del marco de una teoría política que justifique también las otras decisiones que se proponen tomar (Dworkin, 1989, p. 146).

No obstante, ¿qué concepciones políticas y filosóficas orientan a la Corte Constitucional en casos controvertidos? En casos como el de la constitucionalidad de la sanción penal por aborto se pueden identificar toda suerte de argumentos, incluidos los de tipo religioso que conviven con argumentos seculares, los cuales se han fortalecido con el hecho histórico de la entrada en vigencia de la Carta del 91 y con los movimientos ideológicos que se han generado con el reconocimiento del pluralismo político.

En cuestiones divisivas, como la interrupción voluntaria del embarazo, se hace más notorio el problema de las relaciones entre la religión y la idea de un Estado constitucional, pues el debate incorpora las nociones fundantes del proyecto político de la modernidad y los valores democráticos y liberales.En este marco de reflexión, la pregunta rectora que orientó la 
investigación fue: ¿qué postura ha adoptado la Corte Constitucional de Colombia en relación con los argumentos religiosos, a la hora de fundamentar y expresar sus decisiones en algunos casos controvertidos?, ¿los ha adoptado, los ha rechazado o los ha traducido?, ¿qué pueden significar las anteriores opciones?

La reflexión contenida en este artículo producto de investigación se presenta a partir de la descripción, resultado del análisis de distintas fuentes documentales. Con base en dichas fuentes, se reconstruyó un marco teórico que sirve de referente para la formulación de criterios para el análisis crítico del discurso, expuesto en los argumentos de la sentencia C-355 de 2006, que decidió sobre la demanda de inconstitucionalidad contra los Arts. 122, 123 (parcial), 124 (modificados por la Ley 890 de 2004), y 32 numeral 7, de la ley 599 de 2000 Código Penal (referentes al aborto). ${ }^{1}$ Dicho análisis se hace desde una perspectiva cualitativa no probabilística.

Como resultado se pudo concluir, frente al problema planteado que, por un lado, la Corte y los magistrados que aclaran el voto y que representan la posición mayoritaria, sustentan su decisión en una posición constitucionalista, liberal democrática, no secularista, mientras que los magistrados que salvan el voto, argumentan su posición en contra del aborto, desde una convicción que, por sus semejanzas con posiciones religiosas radicales, no puede aceptarse desde el punto de vista constitucional.

Para presentar el desarrollo de lo anterior, se procede de la siguiente manera. (I) Se exponen, desde la perspectiva liberal, el planteamiento de Habermas sobre el papel de la religión en la esfera pública, y la clasificación de los argumentos que, en torno al aborto, ha propuesto Dworkin en su libro El dominio de la vida, (1994) como referente de análisis del discurso de las diferentes tesis en el fallo. (II) Se expone el análisis de los argumentos más relevantes de las consideraciones, los fundamentos y la decisión de la Corte y de las aclaraciones del voto, con el fin de establecer las bases liberales, democráticas y pluralistas que los sustentan como tesis mayoritaria. (III) Se da cuenta del resultado del análisis de los salvamentos de voto, con el fin de indagar acerca de los argumentos más relevantes en contra del aborto y

\footnotetext{
1 El tenor literal del artículo en cuestión era el siguiente: Art. 122. -Aborto. "La mujer que causare su aborto o permitiere que otro se lo cause, incurrirá en prisión de uno (1) a tres (3) años.

A la misma sanción estará sujeto quien, con el consentimiento de la mujer, realice la conducta prevista en el inciso anterior" (Congreso de la República de Colombia, 2000).
} 
determinar desde qué perspectiva se justifica su defensa. (IV) Finalmente, a partir de este análisis, se presentan algunas conclusiones.

\section{La perspectiva liberal de Habermas y Dworkin}

Con el fin de abordar el problema de investigación se analizó la obra de Habermas, quien ha revisado el papel de la religión en relación con la modernidad y la democracia.

Para este autor, al nivel de la "esfera pública informal", ${ }^{2}$ los ciudadanos religiosos y seculares tienen ciertas obligaciones que deben cumplir, si quieren participar de un discurso libre, informado y democrático.

Por una parte, los ciudadanos religiosos pueden expresar y justificar sus convicciones en un lenguaje religioso, si no logran traducir en términos seculares sus ideas, pues los ciudadanos seculares, como ciudadanos democráticos, deben abrir su mente a dichos argumentos. Esto, en concordancia con ciertos deberes de los ciudadanos no religiosos: a) aceptar que los ciudadanos religiosos tienen derecho a contribuir en los debates políticos públicos, expresándose en términos religioso. b) aceptar el potencial de verdad de las concepciones religiosas, y c) participar en los esfuerzos por traducir los argumentos religiosos relevantes a un lenguaje públicamente accesible. (Habermas, 2006, p. 119).

Desde la perspectiva de Habermas, dado el pluralismo religioso propio de las sociedades contemporáneas, el avance de las ciencias modernas y el establecimiento del derecho positivo y la moral secular social, los ciudadanos religiosos tienen que cumplir también con algunos deberes con el fin de actuar como ciudadanos democráticos. Estos deberes son: a) aceptar la existencia y validez de otras religiones, b) reconocer la independencia y autonomía del conocimiento secular, c) reconocer la primacía de las razones seculares en los debates políticos, producto de las nociones de derecho racional y de la moral universalista.

2 El concepto de "esfera pública informal" hace parte del lenguaje filosófico de la teoría de la democracia deliberativa de Habermas. La expresión "esfera pública formal", en contraste, es una expresión presentada por la filósofa Cristina Lafont para desarrollar su interpretación (Ver Lafont, 2007; 2009) y que resulta bastante útil para explicar el alcance de la perspectiva de Habermas. 
Pese a esta "apertura" hacia la religión, Habermas mantiene la tradición liberal en la "esfera pública formal", ámbito institucional en el que se desarrollan los debates del congreso, la argumentación judicial, los debates colectivos en las cortes y, en general, en la administración estatal. En estos espacios todo debe expresarse en un lenguaje accesible a todos los ciudadanos, de manera que una ley o sentencia no podría justificarse en argumentos religiosos. ${ }^{3}$

Uno de los principales objetivos de nuestra investigación fue analizar qué tan pertinente resulta el marco filosófico propuesto por Habermas para analizar discusiones jurídico-políticas reales, en las cuales los argumentos religiosos desempeñaron un papel muy relevante. Una de estas discusiones, como es sabido, es la discusión sobre el aborto.

Ahora bien, antes de realizar este análisis, debemos señalar que, en el desarrollo de la investigación se decidió, para el caso concreto del análisis de la sentencia C-355 del 2006, complementar la perspectiva de Habermas con la visión del filósofo del Derecho norteamericano Ronald Dworkin. Para esto se tuvieron básicamente dos razones.

En primer lugar, la teoría de la democracia de Habermas, en lo referente al papel de los tribunales constitucionales, se desarrolla a partir de un diálogo crítico con Ronald Dworkin (Habermas, 2001, pp. 326-339). El filósofo alemán acepta, en términos generales, la idea de Dworkin según la cual en el derecho existen "respuestas correctas". Sin embargo, Habermas pretende superar las consecuencias monológicas de la perspectiva de Dworkin a partir de una teoría discursiva y comunicativa del derecho (Mejía Quintana, 2012).

En segundo lugar, debemos señalar que la perspectiva de Habermas sobre el aborto es ambigua. El filósofo se ha referido de forma explícita al tema en dos textos. En el primero se preguntaba por la posible existencia de una única respuesta correcta para la cuestión del aborto. Después de señalar que las dos partes extremas del debate parecen tener argumentos,

3 Habermas coincide con Rawls en este punto, pues para él, “(...) debemos distinguir entre cómo se aplica el ideal de la razón pública a los ciudadanos comunes y cómo se aplica a los diversos funcionarios gubernamentales. Se aplica en los foros y, por tanto, a los legisladores cuando hablan en el recinto del Parlamento, y al Ejecutivo en sus actos y pronunciamientos públicos. Se aplica también, de manera especial, al Poder Judicial y, sobre todo, a la Suprema Corte (...)". (Rawls 1996, p.206207). Para Rawls, la Suprema Corte "constituye el más alto ejemplo de la razón pública aplicada" (Rawls 1996, p. 207). 
"quizá igual de buenos" Habermas sugiere que tal vez lo mejor sea entender el aborto como un asunto ético. (Habermas, 2000, p. 172),

Así, en contraste con la perspectiva moral, para Habermas (2000) la perspectiva ética es aquella que se encuentra inextricablemente entretejida con autodescripciones particulares de personas y de grupos. Desde acá, en vez de una única respuesta correcta, se deben admitir "diferentes respuestas validas, según fuese en cada caso el contexto, el horizonte de tradiciones y el ideal de vida" (Habermas, 2000, p. 172).

Recientemente, Habermas afirma que existe una gran enseñanza que se puede extraer del debate sobre el aborto, a saber, "el fracaso de todo intento de llegar a una descripción cosmovisivamente neutral (es decir, que no prejuzgue) del estatus moral de la vida humana incipiente, una descripción que sea aceptable para todos los ciudadanos de una sociedad secular" (Habermas, 2002, p. 48). La razón por la cual la cuestión del aborto no sería un asunto moral, es por su necesaria presuposición sobre el valor y la descripción ontológica del embrión; un asunto en el que es imposible llegar a un consenso correcto para todos.

En el segundo texto, Habermas cita de forma explícita uno de los trabajos en los que Dworkin (1994) argumenta su visión. ${ }^{4}$ Por esta razón consideramos oportuno analizar directamente la perspectiva de Dworkin para tratar de extraer consecuencias democráticas concretas, para el contexto ético de la sociedad colombiana, que vayan más allá de las restricciones filosóficas que Habermas se impone a sí mismo 5 .

4 Habermas cita el libro "El dominio de la vida: una discusión acerca del aborto, la eutanasia y la libertad individual". Como lo acabamos de señalar, Habermas está de acuerdo con Dworkin acerca de la dificultad, tal vez insuperable, de llegar a un acuerdo en relación con el tema del aborto en virtud de lo que está en juego es, en gran parte, una toma de postura sobre el inicio y el valor de la vida humana. Las tesis principales del libro "El futuro de la naturaleza humana" fueron de hecho discutidas por Habermas en el coloquio Law, Philosophy and Social Theory, dirigido por Ronald Dworkin y Thomas Nagel. Los resultados de esta discusión pueden leerse en el Post Scriptum del libro.

5 En un texto aún más reciente (el discurso en honor de Ronald Dworkin pronunciado por Habermas en el año 2006 con ocasión de la concesión del premio Niklas Luhmann hecha a Dworkin), Habermas ha dicho del jurista norteamericano que "ha seguido siendo un fenómeno excepcional. Es un solitario tanto en el círculo de los juristas como en el de los filósofos, disfruta de una gran reputación entre los intelectuales públicos de su país y es un orador político muy dotado. Con algo menos de brillantez, espíritu crítico y genialidad habría llegado hace ya tiempo a ser juez de la Suprema Corte de Washington. (Habermas, 2009, p. 44). 
Ahora bien, ¿qué tipo de argumentos se han propuesto en el debate en torno al aborto? Para Dworkin, esta discusión se realiza a partir de dos concepciones divergentes: la liberal secular y la que se opone al aborto.

La primera divide los argumentos que sustentan su posición en cuatro partes:

1. El aborto es una "grave decisión moral" y, por lo tanto, no se debe entender como un recurso al cual se puede recurrir por cualquier trivialidad pues constituye un acto que (...) no está nunca justificado, excepto para prevenir un daño serio de cierta clase. (Dworkin, 1994, p. 47).

2. Sin embargo, el aborto está justificado por "(...) un conjunto de razones serias" (Dworkin, 1994, p. 48), como cuando está en inminente peligro la vida de la mujer, cuando la concepción ha sido producto de una violación o cuando se ha diagnosticado que el feto sufre una severa malformación, entre otras.

3. También se justifica la interrupción del embarazo cuando la mujer considera que el nacimiento del niño ocasionará graves y permanentes consecuencias negativas para la realización de sus propios intereses en la vida. La decisión sobre abortar o no es entonces una dura decisión para quien realiza el aborto pero se asume como válida y necesaria. (Dworkin, 1994, p. 48).

4. Finalmente, se parte de la opinión política según la cual la mujer debe tener el derecho a decidir por sí misma si desea o no continuar con el embarazo. Ni el Estado, ni la familia, ni la opinión pública, ni ningún tercero pueden imponerle sus convicciones morales. (Dworkin, 1994, p. 48,49$)$.

Como regla general, según el filósofo, la opinión liberal es fundamentalmente contradictoria con "(...) cualquier suposición de que el feto durante su etapa inicial es una persona con derechos e intereses propios" (Dworkin, 1994, p. 49).

Con respecto a la posición que se opone el aborto, Dworkin la divide en dos concepciones que se diferencian respecto al criterio que justifica su postura. De una parte se encuentran aquellos que defienden una objeción que se define como de "carácter derivado" y, de otra, quienes plantean una objeción de "carácter autónomo". 
1. La objeción de carácter derivado es aquella según la cual el gobierno es responsable de defender a los fetos en cuanto estos, desde el momento mismo de la concepción, son personas como cualquier otro ser humano adulto; por tanto, interrumpir un embarazo viola el derecho a la vida garantizado a todos por el orden constitucional y legal.

2. La objeción de carácter autónomo es aquella que plantea que "la vida humana tiene un valor intrínseco, innato; que la vida humana es sagrada en sí misma, y que el carácter sagrado de la vida humana empieza cuando se inicia su vida biológica (...)". (Dworkin, 1994, p. 19). El Estado debe proteger la vida del feto por el hecho mismo del valor intrínseco, autónomo que tiene la vida misma. Sin embargo, esta tendencia opositora al aborto no cree que el feto sea ya "algo que tiene intereses y derechos".

Para Dworkin, esta última posición en contra del aborto puede ser perfectamente compatible con la tradición de las modernas democracias pluralistas de la libertad de conciencia en cuanto acepta, como lo hace la posición liberal, que el aborto no es deseable y que solo se justifica en casos de extrema gravedad. Por ello no es equiparable a ningún otro medio de prevención anticonceptiva e implica siempre un dilema moral que la mujer debe absolver y con el cual tendrá que vivir siempre.

De esta manera, solamente la posición dura de "carácter derivado", supone una negación radical del aborto, al que consideran como un grave homicidio que el Estado tiene que sancionar a través de la ley penal (Dworkin, 1994, p. 24).

Es así, entonces, que la posición liberal se contradice radicalmente con la visión según la cual el feto es persona desde el momento de la concepción y por lo tanto tiene intereses y derechos como cualquier persona adulta. En efecto, como se expuso, para esta última perspectiva, todo aborto es un mal que debe ser castigado penalmente como cualquier homicidio en cuanto niega o viola el derecho más importante de todos los derechos fundamentales: el derecho a la vida.

Las preguntas que resulta importante dilucidar entonces son, ¿cómo interpretar la tesis defendida por los magistrados en la posición mayoritaria, en las aclaraciones del voto y en los salvamentos de voto de la sentencia sobre el aborto?, ¿qué perspectiva en torno al aborto defiende: la liberal, la de carácter derivado o la de carácter autónomo? 


\section{La tesis mayoritaria en la sentencia que liberalizó la interrupción voluntaria del embarazo}

Un asunto inicial que debe ser tenido en cuenta con respecto a la decisión de la Corte Constitucional, en este caso, es el rol de la Constitución en la determinación de lo que es o no correcto en el ámbito de la regulación jurídica. Las decisiones de la Corte tienen gran incidencia en la esfera política y social, como sucede en este caso en donde la Corte modifica el precedente jurisprudencial y define los límites a la potestad de configuración del legislador en materia penal en este caso. ${ }^{6}$

El procedimiento político democrático aparece, desde la perspectiva de Habermas, como un "(...) un proceso de comunicación, razón y persuasión por el cual se deciden cosas de valor, encaminadas a la búsqueda de un acuerdo acerca de una forma buena y justa de vivir" (Letelier, 2011, p. 385). ${ }^{7}$

En este procedimiento, los tribunales constitucionales deben garantizar las condiciones de la discusión pública y del debate parlamentario para que sea el legislador quien decida los asuntos más importantes de la convivencia ciudadana. De esta forma, en principio, estos tribunales no deberían intervenir directamente limitando el poder del legislativo y su capacidad de configuración de la vida social. Para Habermas:

Al Tribunal Constitucional las razones legitimadoras, que tiene que tomar de la Constitución, le vienen dadas desde la perspectiva de la apli-

6 En otras ocasiones, como es bien sabido, la Corte incluso ha llegado a "inmiscuirse" en las potestades del ejecutivo al momento de diseñar políticas públicas. Ver, al respecto, el artículo del profesor Juan Carlos Henao titulado "El juez constitucional: un actor de las políticas públicas" (Henao, 2013).

Ahora bien, esto no puede entenderse enteramente desde el punto de vista republicano. Ver al respecto el capítulo VII de Facticidad y Validez "Política deliberativa: un concepto procedimental de democracia". Alli, frente a los modelos normativos de democracia liberal y republicano, Habermas presenta un tercero construido a partir de la teoría del discurso. Este modelo, en palabras del propio Habermas, "En concordancia con el republicanismo pone en el centro el proceso de formación de la opinión y la voluntad políticas pero sin entender la Constitución articulada en términos de Estado de derecho como algo secundario; antes los principios de! Estado de derecho los entiende, como ya hemos mostrado, como respuesta consecuente a la cuestión de cómo pueden institucionalizárselas exigentes formas de comunicación de una formación democrática de la opinión y la voluntad políticas. El desarrollo y consolidación de una política deliberativa, la teoría del discurso los hace depender, no de una ciudadanía colectivamente capaz de acción, sino de la institucionalización de los correspondientes procedimientos y presupuestos comunicativos, así como de la interacción de deliberaciones institucionalizadas con opiniones públicas desarrolladas informalmente" (Habermas, 2001, p. 374). 
cación del derecho y no de un legislador positivo que ha de interpretar, desarrollar y dar forma al sistema de los derechos al perseguir sus propias políticas. El Tribunal desata y vuelva a atar la gavilla de razones con las que el legislador legitima sus resoluciones, con el fin de movilizarlas a favor de una decisión coherente del caso particular, que concuerde con los principios jurídicos vigentes; pero no puede disponer de esas razones de suerte que sirvan a una interpretación, desarrollo y configuración del sistema de los derechos dependiente directamente del Tribunal y, por tanto, a una actividad legislativa implícita. (Habermas 2001, p.335).

En todo caso, las posibilidades de acción del poder legislativo se encuentran limitadas por la Constitución. Precisamente, uno de los temas de gran controversia, es el referente al aborto, asunto que debería incorporarse en la agenda legislativa, pero que, como lo señala el magistrado Araújo Rentería en su aclaración de voto ni siquiera el Constituyente primario en la Asamblea Nacional Constituyente "(.. a) abordó el tema de inicio de la vida" (Magistrado Rentería, Aclaración de voto. En Corte Constitucional de Colombia, Sentencia C-355 de 2006). En virtud de lo conflictivo del tema se consideró que se requería un análisis posterior para definir políticas claras y lograr consensos en la materia.

Sin embargo, luego de 15 años (al momento de presentación de la demanda contra el tipo penal de aborto), el Congreso no había desarrollado una regulación alternativa a la penal, dejando sin resolver los graves problemas que afrontan las mujeres colombianas frente al aborto, penalizado de manera absoluta. La sanción penal que, si bien estipulaba algunos atenuantes, criminalizaba la conducta en todas sus manifestaciones, por lo que ni los médicos ni las mujeres podían legalmente recurrir a procedimientos para interrumpir un embarazo, sin verse incursos en un proceso penal, además de las consecuencias negativas en el ámbito laboral, familiar, de salud y social.

Frente a este estado de cosas y ante la demanda de inconstitucionalidad en contra del tipo penal de aborto, la Corte Constitucional tuvo que dirimir, no el problema de la política criminal del Estado, sino la constitucionalidad de una cláusula penal, que sancionaba en todos los casos la interrupción voluntaria del embarazo y que colisionaba con derechos fundamentales de las mujeres. 
En este sentido, la concepción deliberativa de Habermas sobre el papel del legislativo como definidor de las reglas sociales no es negada por este fallo en donde la Corte analiza la validez constitucional de la antijuridicidad del aborto en todos los casos. Este análisis de constitucionalidad era apremiante, no para desarrollar reglas en torno al aborto (asunto propio del legislativo), sino para decidir sobre la posible afectación de los derechos fundamentales de las mujeres ante la sanción penal.

La decisión de la Corte constitucional en relación con el problema jurídico planteado, a saber si era constitucionalmente válida la tipificación del aborto como un delito sin excepciones, se funda en tres premisas esenciales:

1. El nasciturus no es persona $\mathrm{y}$, por lo tanto, no es titular del derecho constitucional a la vida, aunque su vida goce de protección. Con esto la Corte se aparta del paralelismo entre el no nacido y la persona.

2. El ejercicio del poder punitivo del Estado expresado en la potestad de configuración normativa del legislador en materia penal está sujeto a restricciones constitucionales y está limitado por los derechos fundamentales.

3. Los ciudadanos, una vez consagrados los derechos, pueden hacerlos valer mediante su participación ciudadana y su compromiso con la defensa de la supremacía e integridad de la Constitución en el debate público.

Estas premisas pueden ser entendidas en el caso concreto desde la perspectiva habermasiana, de la siguiente manera. En el debate público que condujo a la promulgación de la Constitución de 1991 se establecieron unos principios fundamentales de corte liberal, democrático, secular y pluralista, que deben ser respetados. Entre estas garantías se incluye el derecho a la participación política, a partir del cual los ciudadanos pueden presentar demandas de inconstitucionalidad contra las leyes por violación del contenido material de la Constitución o por vicios de procedimiento en su creación. Así las cosas, es coherente, con el principio deliberativo, que los ciudadanos intervengan ante el órgano jurisdiccional para que resuelva si las normas son válidas, teniendo como referente el acuerdo inicial representado en las decisiones tomadas por el Constituyente. Es así que la Corte, en relación al caso concreto del aborto, escucha tanto a quienes están a favor 
de mantener la norma que sanciona el aborto en todos los casos como a quienes piensan que esta medida constituye una injusta discriminación y violación de derechos. Tenemos entonces en esta sentencia una muestra de cómo, en el caso concreto, se vuelve realidad una de las funciones que deber asumir el derecho moderno, a saber, permitir que los ciudadanos exijan el cumplimiento de los derechos fundamentales como garantía del límite de los poderes públicos. ${ }^{8}$ En Colombia esta posibilidad se expresa en su forma más notable en las demandas de inconstitucionalidad, en la medida en que los ciudadanos pueden solicitar el control de constitucionalidad de las leyes y con ello asegurar los límites del poder del legislador:

Los ciudadanos tienen derechos subjetivos, que deben poder hacer respetar a través de mecanismos legales que los garanticen. Este es un elemento fundamental acogido por la Corte en la sentencia sub examine: los individuos tienen derechos subjetivos como parte de su autonomía privada, que deben poder hacer valer en el ámbito público político, social y constitucional. Esta es, como se sabe, la tesis de Habermas sobre la co-originalidad de la autonomía privada y la autonomía pública. ${ }^{9}$

8 En el paradigma deliberativo de la democracia los ciudadanos no son concebidos como meros participantes privados y egoístas en el mercado de bienes y servicios, ni como simples clientes pasivos de las burocracias del Estado social. Los ciudadanos, en contraste, son agentes activos que toman parte "en discursos políticos para hacer valer intereses vulnerados, y que por vía de la articulación de esos intereses cooperan en el desarrollo de criterios concernientes al trato igual de los casos iguales y al trato desigual de los casos desiguales" (Habermas, 1998, p. 525). Por esta razón, como lo señala Habermas, "las opiniones públicas representan un potencial político de influencia que puede utilizarse para ejercer influencia sobre el comportamiento electoral de los ciudadanos o sobre la formación de la voluntad en los organismos parlamentarios, en los gobiernos y en los tribunales" (Habermas, 1998, p. 443). Pues bien, qué mejor forma de tener en cuenta estas opiniones por parte de los tribunales constitucionales que institucionalizando un procedimiento para que ciudadanos "de carne y hueso" intervengan y manifiesten sus propias opiniones. En palabras de Mejía Quintana, "El álter ego del tribunal constitucional no son los meros procedimientos democráticos (democracia formal) ni la voluntad de las mayorías (democracia directa) sino la deliberación ciudadana que se manifiesta en la dinámica comunicativa de la esfera pública" (Mejía, 2012, p. 77).

9 De acuerdo con Habermas, la autonomía pública o política de los ciudadanos, expresada por ejemplo en los derechos de participación política, no puede entenderse en conflicto con su autonomía privada, expresada en los diversos catálogos de derechos fundamentales "individuales". Para Habermas estos conflictos que se suelen encontrar en estos dos ámbitos son fruto de una mala comprensión de los mismos. La teoría de la democracia deliberativa de Habermas busca aclarar lo anterior a partir del recurso a la teoría del discurso. Desde esta perspectiva los ciudadanos solo son autónomos si se conciben a sí mismos, y actúan en concordancia, como autores de los derechos a los que quieren someterse como destinatarios. Pero esto solo lo pueden hacer, en las sociedades contemporáneas pos - convencionales, en el medio del derecho mismo. "De ahí que las condiciones bajo las que los ciudadanos pueden juzgar a la luz del principio de discurso si el derecho que establecen es derecho legítimo, hayan de venir a su vez garantizadas jurídicamente. A esto sirven los derechos políticos fundamentales concernientes a la participación en los procesos de formación 
En este horizonte la Corte pondera la protección que se debe dar a la vida del nasciturus con la garantía que tienen los derechos de la mujer a la dignidad humana, al libre desarrollo de la personalidad, a la salud, la vida y la integridad personal en el marco del bloque de constitucionalidad.

En el caso concreto analizado, la Corte Constitucional realiza una ponderación entre la garantía de protección de la vida del nasciturus, que el Estado debe proporcionar, y los derechos de la mujer embarazada, desde una perspectiva secular, democrática y pluralista, llegando a las siguientes conclusiones:

1. La penalización del aborto, per sé no constituye una violación del Estado a la autonomía privada de la mujer embarazada. Pues, "(...) la vida del nasciturus es un bien protegido por el ordenamiento constitucional y por lo tanto las decisiones que adopte la mujer embarazada sobre la interrupción de la vida en gestación trascienden de la esfera de la autonomía privada e interesan al Estado y al legislador" (Corte Constitucional, sentencia, 10.1. La inexequibilidad de la prohibición total del aborto). En este sentido, el legislador tiene la potestad de penalizar el aborto sin que se pueda entender este hecho como una "(...) medida perfeccionista dirigida a imponer un determinado modelo de virtud o de excelencia humana bajo la amenaza de sanciones penales". (Corte Constitucional de Colombia, Sentencia C-355 de 2006).

2. El problema está en la penalización del aborto en todas las circunstancias, pues con ello se está violando la autonomía privada de la mujer embarazada. En palabras de la Corte:

de la opinión y la voluntad del legislador" (Habermas, 2001: p. 192-193). En otras palabras, en las sociedades contemporáneas en donde las cosmovisiones metafísico-religiosas no fundamentan ya los órdenes políticos, la legitimidad del derecho depende de la formación discursiva de la opinión y la voluntad de ciudadanos dotados de unos mismos derechos. Esto significa que la participación política (autonomía pública) presupone el aseguramiento de la autonomía privada (iguales derechos subjetivos). Pero, a la vez, la autonomía privada solo se entiende y se defiende en el marco del ejercicio democrático participativo. En el presente artículo no podemos profundizar sobre este tema. Al respecto ver el capítulo III de "Facticidad y Validez" titulado Reconstrucción interna del derecho: el sistema de los derechos. Ver también "Debate: The Cooriginality of Private and Public Autonomy in Deliberative Democracy" (Rummens, 2006). Otros textos que analizan el tema del derecho y la filosofía de Habermas y que pueden ser consultados para profundizar esta cuestión son Callejas (2009), Garzón (2012) y Botero (2012), entre otros. 
[...] la penalización del aborto en todas las circunstancias implica la completa preeminencia de uno de los bienes jurídicos en juego, la vida del nasciturus, y el consiguiente sacrificio absoluto de todos los derechos fundamentales de la mujer embarazada, lo que sin duda resulta a todas luces inconstitucional [...] una regulación penal que sancione el aborto en todos los supuestos, significa la anulación de los derechos fundamentales de la mujer, y en esa medida supone desconocer completamente su dignidad y reducirla a un mero receptáculo de la vida en gestación, carente de derechos o de intereses constitucionalmente relevantes que ameriten protección (Corte Constitucional de Colombia, Sentencia C-355 de 2006).

En el mismo sentido, las aclaraciones de voto de los magistrados Jaime Araújo Rentería y Manuel José Cepeda Espinosa señalan que no es constitucionalmente válido sancionar penalmente la interrupción voluntaria del embarazo en todos los casos, por cuanto con ello se violan los derechos subjetivos de las mujeres embarazadas y finalmente su autonomía privada.

El magistrado Jaime Araujo Rentería, sin embargo, introduce una variante argumentativa a la propuesta por la Corte. Hace énfasis en el supuesto de que el nasciturus no es persona y, por lo tanto, no es titular de derechos en la concepción liberal de la persona humana como capaz de autodeterminación y autogobierno. Según su argumentación (que como se verá está diametralmente opuesta a la de los magistrado Marco Monroy Cabra), "(...) el nasciturus es ser protegido por el derecho pero claramente no tienen personalidad" (Magistrado Araújo Rentería. Aclaración de sentencia. En Corte Constitucional de Colombia, Sentencia C-355 de 2006). En este sentido no es procedente realizar ningún ejercicio de ponderación pues claramente no existe conflicto entre esta protección debida a la vida del nasciturus y los derechos de la mujer. Su argumento es el siguiente:

Y no aparejando de suyo la vida la personalidad jurídica, mal puede afirmarse que existe un conflicto de derechos entre un ser que está por nacer que no tiene personalidad jurídica ni derechos ni obligaciones y una mujer que tiene personalidad jurídica y por consiguiente posee derechos y obligaciones. En otras palabras, no puede haber conflicto de derechos ni ponderación de estos por cuanto los supuestos son diferentes.

De otro lado no sobra recordar que quien tiene personalidad jurídica tiene un derecho cierto- no probable- a la vida y a otros derechos funda- 
mentales como a la libertad (en todas sus especificaciones), a la igualdad, a la salud, a la dignidad, etc. (Magistrado Araújo. Aclaración de voto. En Corte Constitucional de Colombia, Sentencia C-355 de 2006).

Luego de esta afirmación del nasciturus como un ser vivo, pero sin la caracterización de persona titular de derechos y obligaciones jurídicas, el magistrado se concentra en mostrar cómo debe resaltarse en forma especial la autonomía privada de la mujer embarazada. En este propósito se vale de la argumentación kantiana según la cual el ser humano tiene la obligación de valerse por su propia razón de la cual debe hacer uso. Así, el Estado y la sociedad deben garantizar este derecho fundamental, pues es la base de la auténtica libertad. De ahí la obligación de restringir la potestad del legislador para intervenir en los asuntos que afectan fundamentalmente al individuo. Esto es además, un requisito de la democracia, pues, como afirmara también Rawls, en un régimen de libertad, el primer principio, el deber de garantizar la mayor libertad posible a los individuos, prevalece sobre las demás consideraciones de orden material, esa prevalencia se ha identificado con cierto orden en la aplicación de los principios, de tal manera que "el segundo principio de justicia está subordinado al primero, pues el primero garantiza las libertades básicas necesarias." (Rawls, 1990, p. 12). En este sentido las palabras del magistrado son claras:

Pues, en una democracia resultante de un Estado Social de Derecho, y estructurada en el principio de la libertad, las restricciones a esta solamente pueden estar presentes si existe una necesidad constitucional para la seguridad de otro.

Así las cosas, en el evento en el cual la necesidad que se plantea es incierta debe operar de manera inmediata el principio in dubio pro libertate (la duda a favor de la libertad). Por consiguiente, quien desee limitar la libertad, posee la carga de demostrar que la necesidad de dicha limitación tiene carácter constitucional. Por el contrario, quien desee mantener la libertad no posee carga alguna en materia probatoria, por cuanto esta es la base estructural de la democracia (Magistrado Araújo. Aclaración de voto. En: Corte Constitucional de Colombia, Sentencia C-355 de 2006).

De esta manera tenemos una argumentación, por parte del magistrado Araújo, basada esencialmente en los derechos de libertad, democracia, dig- 
nidad humana, autonomía y libre desarrollo de la personalidad de la mujer embarazada. No puede, entonces, según esta forma de entender los fundamentos de un Estado Social de Derecho, ponerse sobre la misma balanza el deber de protección al nasciturus y los derechos constitucionales de la mujer embarazada, porque en este último caso se trata de derechos ciertos y esenciales de una sociedad bien ordenada, cuya garantía constituye, a su vez, la condición de posibilidad de todo ordenamiento jurídico válido.

Es en este marco jurídico conceptual que este magistrado niega toda pretensión paternalista frente a la mujer o cualquier otro ciudadano [concepción diametralmente opuesta, como se verá adelante a la del magistrado Tafur Galvis]. Así afirma que la dignidad humana se funda en la libertad sobre sí mismo, lo cual fue establecido en el preámbulo de la Constitución, en la medida en que establece que el fin del Estado es la libertad y la base de este derecho está dada por la fórmula kantiana según la cual nadie puede obligar a otro a ser feliz a su manera, por lo que cada cual debe poder buscar la felicidad de acuerdo al camino que a bien tenga escoger con la condición que respete la libertad que los demás tienen de hacer lo mismo, esto es, buscar y seguir su propio camino hacia la felicidad.

En consecuencia, un Estado Constitucional Democrático debe respetar los propósitos y fines plurales de sus individuos y garantizar de esta manera que los parámetros establecidos también sean protectores de un individuo libre (...) Pues bien, la consagración constitucional de este derecho fundamental implica un repulsión hacia aquellas tendencias que creen conocer en mejor manera qué les conviene a las personas y lo que deben hacer con sus vidas. En otras palabras, lo que determina la constitución es que "cada ser humano es mejor juez de sus propios intereses (Magistrado Jaime Araújo Rentería. Aclaración de voto En: Corte Constitucional de Colombia, Sentencia C-355 de 2006).

Tenemos, entonces, que la regulación del aborto no debe partir, para este magistrado, de la consideración de unos supuestos derechos de los cuales es titular el nasciturus sino de los derechos fundamentales de la mujer. Son precisamente las consideraciones respecto a los mismos que sirven de parámetros para establecer los límites a la potestad del legislador en asuntos penales y las condiciones en las cuales la mujer puede, libremente, decidir si aborta o continúa con el embarazo. 
Por su parte, en su aclaración de voto, el magistrado Manuel Cepeda propone una argumentación fundada en el supuesto habermasiano de que es el legislador quien debe debatir y definir las regulaciones de la vida social, por cuanto la Corte no entra a establecer la norma, sino a determinar los límites o las prohibiciones a su potestad de configuración en materia penal. En este sentido la Corte en el caso concreto define dos prohibiciones:

1. "[...] le está prohibido al legislador optar por posiciones absolutas, bien para proteger la vida del feto o bien para garantizar la libertad de la mujer". (Magistrado Manuel J. Cepeda. Aclaración de voto. En Corte Constitucional de Colombia, Sentencia C-355 de 2006)

2. “[...] la Constitución permite que el legislador vaya más lejos en la formulación de su política pública en esta materia, pero le prohíbe tratar como delincuente tanto a la mujer que expresa su voluntad libre de interrumpir el embarazo en las tres hipótesis mencionadas, como al médico que le practica el aborto". (Magistrado Manuel J. Cepeda. Aclaración de voto. En Corte Constitucional de Colombia, Sentencia C-355 de 2006).

Queda clara, entonces su posición liberal de defensa de los derechos fundamentales de la mujer embarazada (autonomía privada) en cuanto se prohíbe que sea considerada, por parte del legislador, como delincuente, en el caso de optar libremente por la interrupción del embarazo en los tres casos extremos que propone la Corte constitucional. De igual forma, si bien considera el aborto como una decisión difícil y grave que las mujeres deben tomar y que trae consecuencias que deben ser valoradas por su importancia social, sin embargo, no excluye su práctica como posibilidad sino que lo considera permitido dada una situación de hecho extrema. Esto es, dadas unas circunstancias serias que deben ser tenidas en cuenta en la medida en que conducen a un juicio de antijuridicidad de la conducta.

\section{Las tesis disidentes no liberales}

El salvamento de voto de los magistrados Marco Monroy Cabra y Rodrigo Escobar Gil se estructura en torno a los siguientes lineamientos conceptuales: 
1. El derecho a la vida del nasciturus prevalece sobre la libertad, la salud y el libre desarrollo de la personalidad de la mujer. El nasciturus es persona con derechos e intereses propios. Esta constituye la premisa fundamental de la cual todas las demás se desprenden.

Los magistrados que salvamos el voto consideramos constitucionalmente inaceptable la distinción planteada en la Sentencia, según la cual la vida del ser humano es tan solo un "bien jurídico", al paso que la vida de las personas capaces de vida independiente sí constituye un derecho subjetivo fundamental. A nuestro parecer, la vida humana que aparece en el momento mismo de la concepción constituye desde entonces y hasta la muerte un derecho subjetivo de rango fundamental en cabeza del ser humano que la porta, y en ningún momento del proceso vital puede ser tenida solamente como un "bien jurídico", al cual pueda oponerse el mejor derecho a la vida o a la libertad de otro ser humano (Magistrados Monroy Cabra y Escobar Gil, Salvamento de voto. En Corte Constitucional de Colombia, Sentencia C-355 de 2006).

Esta posición de los Magistrados Monroy y Escobar se expone en el punto 2 del salvamento de voto, cuyo título es ya bastante ilustrativo: "La vida como derecho subjetivo fundamental de un ser humano desde el momento mismo de la concepción, y no como simple bien constitucionalmente relevante". (Magistrados Monroy Cabra y Escobar Gil, Salvamento de voto. En Corte Constitucional de Colombia, Sentencia C-355 de 2006)

2. La mujer debe asumir una responsabilidad legal frente a la vida que lleva en el vientre, pues la vida del nasciturus es, desde un inicio, un ser independiente de la madre, por lo que esta debe asumir la carga sin potestad decisoria sobre su desarrollo y nacimiento ${ }^{10}$.

10 Un desarrollo de este tipo de argumentación puede encontrarse, por ejemplo, en el artículo "¿Es el aborto un derecho sexual y reproductivo de la mujer? Análisis desde el bioderecho, la Bioética, la biopolítica y la biojurídica en Estados Unidos, España y Colombia" (Zárate, 2014). Allí, la autora concluye que "Teniendo en cuenta que el derecho de decisión que le asiste a la mujer sobre su reproducción y su cuerpo termina donde comienzan los derechos del nasciturus, cuyo límite se presenta en el instante mismo de la fecundación, el aborto no puede considerarse como un derecho humano; de lo que se trata es de la "pena de muerte prenatal", la palmaria violencia que ejerce la madre sobre el ser humano que se gesta en su vientre. Jamás podría considerarse como un derecho quitarle la vida a un miembro de su misma especie Homo sapiens-sapiens. Por tanto, bajo ninguna consideración deben ponderarse los derechos de un ser humano por encima del derecho a la vida de otro ser humano. La vida humana no se pondera, 
Ciertamente, al parecer de los suscritos el Derecho tiene como función aliviar los padecimientos humanos y procurar el bienestar de los asociados. Sin embargo, esta finalidad no puede ser entendida en términos absolutos, porque al Derecho solo le es dado perseguir estos fines en cuanto sea posible alcanzarlos a través de medios lícitos, es decir no contrarios a los derechos de terceros. En caso contrario, no queda más que padecer o tolerar ciertos males, que comparados con el daño jurídico que supone el quebrantamiento de derechos fundamentales de otros, y con ello del orden social justo, deben ser considerados males menores (Magistrados Monroy Cabra y Escobar Gil, Salvamento de voto. En: Corte Constitucional de Colombia, Sentencia C-355 de 2006).

Esta posición de los magistrados los lleva, en últimas, a una conclusión radical según la cual “( ...) en ningún caso la conducta directamente occisiva sobre un individuo no nacido de la especie humana se puede justificar en aras de la prevalencia de los derechos de su madre" (Magistrados Monroy Cabra y Escobar Gil, Salvamento de voto. En Corte Constitucional de Colombia, Sentencia C-355 de 2006).

Partiendo, entonces, de la premisa según la cual el feto es un ser humano con plenos derechos como persona, se critica la decisión de la Corte en los siguientes términos:

Así pues, el argumento para obviar la indiscutible obligación legislativa de proteger la vida en formación consistió en separar las nociones de persona humana y de la vida, con el objeto de dar un supuesto fundamento constitucional a la desprotección jurídica del no nacido, en aras de la prevalencia de la autonomía, la libertad, el libre desarrollo de la personalidad o la salud de la madre (Magistrados Monroy Cabra y Escobar Gil, Salvamento de voto. En Corte Constitucional de Colombia, Sentencia C-355 de 2006).

Siendo la vida un derecho absoluto, no puede ser susceptible de ninguna ponderación, pues no habrá ninguna situación real o legal que pueda ser puesta a un escrutinio de proporcionalidad. En efecto, en todos los casos "(...) el sacrificio o afectación de derechos del feto resulta superior al

se respeta" (Zarate, 2014, p. 22). En este texto, como es evidente, presentamos una visión diferente del tema que no busca otra cosa sino contribuir a un debate que reconocemos amplio, complejo y difícil. 
beneficio obtenido" (Magistrados Monroy Cabra y Escobar Gil, Salvamento de voto. En Corte Constitucional de Colombia, Sentencia C-355 de 2006) en cualquier sentido estricto de proporcionalidad. Para los magistrados, con el aborto, se está frente a un sacrificio del feto-persona de intensidad máxima, frente al cual cualquier beneficio para la mujer sería solamente eventual o probable, no cierto.

Es crucial evidenciar que este argumento coincide en su conclusión con los argumentos de tipo religioso propuestos por la Conferencia Episcopal Colombiana, cuyo secretario general, monseñor José Daniel Falla, afirmaba lo siguiente: "Estoy en contra del aborto. Ninguna circunstancia, por grave que parezca, puede justificar ni convertir en legal o moralmente aceptable el hecho de causar intencionalmente la muerte a un ser humano inocente" (Herrera, 2012).

Esta coincidencia naturalmente no descalifica per se el argumento de estos Magistrados, ni lo convierte de inmediato en un argumento religioso. Sin embargo esta coincidencia casi total sí puede servir para explicar por qué, al final de este proceso, esta argumentación no se pudo imponer como vencedora en el plano de la razón pública institucional en donde deben primar argumentos basados en los fundamentos liberales de una democracia constitucional.

Como lo señala Dworkin, las argumentaciones absolutamente prohibitivas del aborto, explícitamente religiosas o no, son siempre problemáticas y no porque sean religiosas sino porque son absolutas. En palabras del mismo Dworkin, en estos casos extremos, "un gobierno que criminaliza el aborto niega el libre ejercicio de la religión tanto a estas mujeres" como a las que conscientemente extraen sus opiniones acerca del aborto de la fe religiosa" (Dworkin, 1994, p. 215).

Por su parte, los argumentos del magistrado Tafur parten, en su salvamento de voto, del reconocimiento de la posibilidad constitucional de incluir excepciones a la garantía de la vida que tiene el feto desde el momento de su concepción. En efecto, luego de realizar un análisis sobre el bloque de constitucionalidad de la norma superior colombiana afirma:

11 Mujeres que no necesariamente basan sus decisiones de abortar en reflexiones sobre el carácter sagrado de la vida humana. 
[...] resulta claro que en el contexto de los instrumentos llamados a integrar el bloque de constitucionalidad podrían establecerse excepciones legítimas a la garantía del derecho a la vida de quien está por nacer. Excepciones que obviamente tendrán que ser claramente regladas y ajenas a cualquier capricho, provenga este del Estado, de la madre o de cualquier otra fuente. (Magistrado Tafur, Salvamento de voto. En Corte Constitucional de Colombia, Sentencia C-355 de 2006).

Esto quiere decir que, para el magistrado, la garantía de la vida del feto no supone su defensa a ultranza y de manera absoluta sino que en ciertos casos y en ciertas circunstancias otros valores podrían prevalecer sobre él, "pero siempre de manera excepcional". Estas excepciones tienen que ver, sin embargo, fundamentalmente con asuntos relacionados con las afectaciones a la salud y la vida de la mujer.

Ahora bien, el asunto problemático, para el magistrado, consiste en que si se quiere tener una reglamentación seria y apropiada a esa excepcionalidad de la posibilidad del aborto, el Estado debe desarrollar una política integral que haga referencia no solamente al factum del aborto como tal, sino a todos los demás elementos sociológicos y fenomenológicos que el mismo acarrea. Esa política debe ser desarrollada, según su opinión, en el marco de la actividad propia del legislador. En efecto, considera un error que la Corte Constitucional dé vía libre a excepciones a la garantía de la vida que tiene el feto sin que se haya desarrollado esa necesaria política pública respectiva. Se requiere entonces una regulación detallada sobre el cómo y el cuándo el aborto se justifica, y esta regulación es propia del legislador. La argumentación del magistrado Tafur se funda entonces en el reclamo de una regulación integral del tema del aborto:

[...] es forzoso concluir que en Colombia sólo el legislador puede desarrollar una normativa coherente sobre el tema, que además de la política criminal comprenda aspectos concernientes con la dignidad y la vida de la mujer, así como con los recursos y las políticas necesarias para que el estado garantice en condiciones adecuadas a la mujer el goce responsable de su sexualidad, de su potencial de maternidad y a quienes están por nacer condiciones adecuadas de desarrollo, aún en aquellos supuestos de embarazos no deseados (...) (Magistrado Tafur, Salvamento de voto. En Corte Constitucional de Colombia, Sentencia C-355 de 2006). 
En este sentido, afirma, el aborto no puede ser la única estrategia que garantice la dignidad, la libertad y el libre desarrollo de la personalidad de la mujer, a la vez que haga efectiva las condiciones de vida digna del feto, pues se trata de un asunto complejo que involucra la política del Estado en salud pública, educación, búsqueda de la igualdad real de la mujer, desarrollo de la familia, etc. De igual forma deben tenerse en cuenta, según el magistrado, la importancia de las políticas públicas relacionadas con la prevención de los embarazos no deseados, la información sobre métodos anticonceptivos, y la lucha contra enfermedades que ocasionan embarazos de alto riesgo, entre otras medidas propias de un Estado Social de Derecho. El problema con la sentencia es, entonces, que todos estos asuntos son ajenos al "ámbito funcional de la Corte Constitucional" y abre una compuerta sin sus respectivas bisagras y cerrojos y sin las condiciones reglamentarias de su funcionamiento, para la práctica indiscriminada del aborto.

Hasta aquí se podría decir que el argumento del magistrado es fundamentalmente procedimental y coincidiría, en cierta manera, con la idea habermasiana de la prioridad de la potestad legislativa en la regulación de la vida social.

Su argumento, sin embargo, es en el fondo, contrario a los principios netamente liberales en relación con la admisibilidad del aborto, pues considera que el derecho a la vida de quien está por nacer debe primar sobre los derechos de la mujer a su libertad, dignidad y libre desarrollo de la personalidad. El argumento es el siguiente:

[...] es necesario reafirmar que en el ámbito del derecho interamericano las decisiones de las mujeres respecto del aborto no son absolutas y que las circunstancias en que este puede llegar a ser admisible deber estar claramente regladas y ser excepcionales. Dentro de este ámbito normativo, parece indudable que ha de primar la garantía del derecho a la vida de quien está por nacer, frente al derecho a la libre determinación de la mujer que desea poner fin a una gestación que no desea (Magistrado Tafur, Salvamento de voto. En: Corte Constitucional de Colombia, Sentencia C-355 de 2006).

Igualmente, su argumentación termina formulando una premisa netamente paternalista, en cuanto que, conforme a lo propuesto por las posturas 
religiosas, considera la necesidad de un fortalecimiento de la mujer de manera "integral" para, de esta manera, resolver el "problema del aborto" sin necesidad de admitir su legalidad en ciertas circunstancias. En este sentido afirma lo siguiente:

Tampoco puede interpretarse una política legislativa restrictiva del aborto como una garantía orientada exclusivamente a garantizar la vida del nasciturus. Las mismas restricciones pueden encontrar su razón de ser en la indispensable necesidad de estructurar líneas de acción que fortalezcan a las mujeres como únicas dueñas y responsables de su sexualidad y de la decisión de engendrar o no un hijo y que conduzcan a reformular los patrones de opresión que suelen presentarse en las relaciones entre hombres y mujeres (Magistrado Tafur, Salvamento de voto. En Corte Constitucional de Colombia, Sentencia C-355 de 2006).

Se tiene así, entonces, el recurso, por parte del magistrado Tafur, a un argumento de tipo perfeccionista, que considera que el derecho a la vida del feto prima sobre los derechos de la mujer y supone que lo que debe consolidarse son unas condiciones sociales ideales que permitan que el aborto no ocurra o no sea necesario. En este sentido, su penalización no atenta ni contra la dignidad de la mujer ni contra su intimidad por cuanto, concluye, "(...) todo depende de otras politicas que el Estado a través del órgano idóneo establezca y desarrolle para fortalecer a la mujer de manera integral" (Magistrado Tafur, Salvamento de voto. En Corte Constitucional de Colombia, Sentencia C-355 de 2006).

Esta posición del magistrado coincide integralmente también con la posición de la Conferencia Episcopal Colombiana, cuyo secretario general, monseñor José Daniel Falla, afirma lo siguiente en relación con lo que había que hacer para resolver el "problema" del aborto en Colombia:

En primer lugar, se requiere una adecuada educación afectiva y sexual, basada en una visión integral del ser humano, de su dignidad y de sus valores. En segundo lugar, brindar ayuda a las madres que, en su desesperación, consideran que la única solución a sus problemas es abortar. En tercer lugar, hay que dejar de malgastar cuantiosos dineros, tanto públicos como privados, en la promoción del aborto e invertirlos en la tutela de los auténticos derechos e intereses de la mujer. (Herrera, 2012). 
Se trata, entonces, tanto para el magistrado Tafur, como para el Episcopado Colombiano, de promocionar los "auténticos derechos e intereses de la mujer", que, al parecer, terminarían coincidiendo naturalmente con los supuestos religiosos que deberían primar sobre los derechos e intereses de las mujeres, no religiosas o incluso religiosas que se apartan de la visión dominante como es el caso concreto del grupo de "Católicas por el derecho a decidir".

De hecho, Habermas criticaría, en términos generales, la posición paternalista (en este caso propuesta por el magistrado Tafur y por el Episcopado Colombiano), en la medida que, según él, en un Estado democrático de derecho el discurso de los derechos se funda siempre en la garantía de los derechos subjetivos de los ciudadanos. Y esta garantía supone que puedan desenvolver en forma autónoma sus vidas en lo privado. A su vez, la capacidad del desenvolvimiento autónomo de la vida privada por parte de los ciudadanos supone, necesariamente, que sean los propios afectados por una determinada regulación jurídica quienes articulen y fundamenten, en el debate público, "(...) los correspondientes aspectos relevantes para el tratamiento igual y desigual de los casos típicos. La autonomía privada de los ciudadanos que disfrutan de iguales derechos solo puede ser asegurada activando al mismo compás su autonomía ciudadana". (Habermas, 1999, p. 194). En este sentido, deberían ser las mismas mujeres quienes de forma endógena, en el ámbito del debate público, decidan sobre las condiciones de tiempo, modo y lugar en las cuales se permita o no el aborto. Tratar el problema como si fuera un asunto de incapacidad de la mujer, por falta de educación o "formación integral", para decidir por sí misma, supondría considerarlas en minoría de edad, no aptas para hacer uso de su propia capacidad reflexiva y ejercer sus derechos políticos.

Se identifica también, claramente, en los argumentos del magistrado Tafur, una argumentación típicamente religiosa que pretende ser aplicada y traducida a los parámetros públicos del debate constitucional. Esta argumentación cumple, sin dudas, la exigencia de traducción de la propuesta de Habermas, pero, a su vez, también deja al descubierto las limitaciones profundas de toda actividad de traducción. 


\section{Conclusiones}

El debate en torno a la interrupción voluntaria del embarazo y su regulación es complejo y profundamente problemático. ${ }^{12}$ Los dos autores escogidos para realizar nuestro análisis coinciden en lo anterior. En el caso de Colombia, y en especial de la Sentencia C-355 del 2006 se han presentado una gran cantidad de análisis con muy variadas perspectivas. La que acá se presenta se realiza desde la perspectiva de dos filósofos políticos y derecho contemporáneo, Jürgen Habermas y Ronald Dworkin, en especial a partir de la propuesta del primero sobre el rol de la religión en la esfera pública complementada con la tipología de argumentos alrededor del aborto construida por el segundo.

De lo expuesto se puede concluir que la decisión mayoritaria de la Corte y de los magistrados que aclaran el voto se funda en argumentos propios del liberalismo democrático pluralista, pues este supone que los ciudadanos "(...) en tanto libres e iguales en derechos, deberán estar en libertad de hacerse cargo de sus vidas y podrán exigir que se les garanticen los bienes primarios que les permitan desarrollar sus específicas concepciones del bien, compatibles con los principios públicos de la justicia y de acuerdo al procedimiento establecido en la ley". (Silva, García y Martínez, 2005, p. 164). En este marco, su argumentación rechaza las opciones perfeccionistas y paternalistas que intentan promover una concepción de la vida buena basada en principios religiosos o morales que, en últimas, violan los derechos que se desprenden de los principios de igualdad y libertad que fundamentan un orden constitucional democrático. Concepciones que, en términos de Habermas, privilegian "lo bueno" sobre "lo justo".

Esta es una posición liberal, como se ha visto en la clasificación propuesta por Dworkin, en cuanto no desvirtúa la gravedad del hecho del aborto, pero deja a la mujer la responsabilidad de la decisión y le permite, de acuerdo a sus criterios propios y autonomía práctica, decidir en última instancia lo que es correcto e incorrecto para ella en una situación concreta. El hecho que sea permitido el aborto en algunos casos graves no quiere

12 Se puede consultar, entre otros: Valdés, M. (2001) Aborto y personas. En Controversias sobre el aborto, México, D.F.: Fondo de Cultura Económica; Laurence, H. (2012). El aborto: guerra de absolutos, México: Fondo de Cultura Económica; Carpizo, J. E Valdés, D. (2008) Derechos Humanos, aborto y eutanasia, México: Universidad Nacional Autónoma de México. 
decir que no implique una decisión difícil que solo la mujer debe poder realizar de forma autónoma y libre.

Es una posición concreta y mediadora que, en última instancia, recoge la siguiente observación de Habermas:

Nadie duda del valor intrínseco de la vida humana antes del nacimiento, se la denomine «sagrada» o se rechace esta «sacralización» de lo que es un fin en sí mismo. Pero la sustancia normativa de la protegibilidad de la vida humana prepersonal no encuentra una expresión racionalmente aceptable para todos los ciudadanos ni en el lenguaje objetivante del empirismo ni en el lenguaje de la religión. (Habermas, 2002, p. 49-50).

En otras palabras, se trata de una posición que, ante este hecho inevitable del desacuerdo profundo entre los ciudadanos, trata de producir un "punto medio" que siempre será conflictivo pero que, a la vez, creará un espacio provisional en el que tanto los ciudadanos seculares como los ciudadanos religiosos se pueden considerar a sí mismos como autores de la Constitución.

Por el contrario, la posición de los magistrados que salvan el voto se fundamenta en lo que Dworkin llama el "carácter derivado". En qué medida un argumento "derivado" es necesariamente religioso es una cuestión que dejamos abierta en el presente análisis. Simplemente quisimos notar la coincidencia entre esta clase de argumentos y todos los demás que, religiosos o no, pretenden defender una prohibición total de la interrupción voluntaria del embarazo y que el Estado debe sancionar dicha acción incluso con la ley penal. Así, la conclusión principal a la que llega este artículo es que este tipo de argumentos contradicen los principios de las democracias liberales contemporáneas y, por ende, desde el punto de vista de la propuesta de Habermas sobre el rol de la religión de la esfera pública, deben ser considerados argumentos no válidos en ámbitos institucionales tales como los debates de los tribunales constitucionales.

En efecto, el salvamento de voto de los magistrados Monroy Cabra y Escobar Gil, tiene como pivote argumentativo una concepción que es profundamente antiliberal. Es por esto que podría asemejarse a un argumento que presenta una traducción de una concepción religiosa restrictiva que parte de un principio absoluto e innegociable, el cual trata de ser mantenido incluso después de la traducción. 
Por su parte, el salvamento de voto del magistrado Tafur representa una posición que puede ser considerada como perfeccionista, pues si bien argumenta que el derecho a la vida del feto no es absoluto, niega la posibilidad de despenalizar el aborto en cualquiera de las tres causales que permiten a la mujer, de acuerdo con el fallo, decidir libremente la interrupción del embarazo en las circunstancias establecidas. Sus argumentos son, además, fundamentalmente paternalistas en relación con el rol de mujer frente a la maternidad. Es todo lo anterior, lo que en última instancia, lo que los hace minoritarios en el espacio de la argumentación de la Corte Constitucional de Colombia.

\section{Referencias}

Aguirre, J. (2012). Habermas y la religión en la esfera pública. Ideas y Valores, LXI, (148), pp. 59-78

Aguirre, J. (2013). Habermas' Account of the Role of Religión in the Public Sphere: a Response to Cristina Lafont's critiques through an illustrative political debate about same sex marriage. Philosophy Social Criticism, 39 (7), pp. 637-673

Atienza, M. (2005). Argumentación Jurídica y Estado Constitucional. En M. Añón, G P. Miravet (Ed.). Derechos, justicia y Estado constitucional. Un tributo a Miguel C. Miravet, Valencia: Tirant Lo Blanch, pp. 25-34.

Botero, A. (2012). Introducción iusfilosófica y crítica a la obra "Facticidad y Validez" de Habermas. En Botero, A. (Coord.). Filosofía del derecho. Medellín: Universidad de Medellín, pp. 687-752.

Callejas, J. (2009). Fundamentación racional de las decisiones judiciales a partir de Habermas: hacia la construcción de un consenso basado en la diversidad étnica y cultural. Revista Sin Fundamento, Universidad Libre, Bogotá. (11), 14-32. Corte Constitucional de Colombia. (2006). Sentencia C-355.

Durango Álvarez, G. (2007). Estado democrático de derecho - Estado constitucional de derecho: ¿Tensión entre el desarrollo y garantía de derechos fundamentales? Revista de derecho. Ediciones Uninorte, 28 (1), pp. 88-111.

Durango Álvarez, G. (2010). El concepto de los derechos fundamentales en la teoría habermasiana: de la Acción comunicativa a Facticidad y validez. Revista de derecho, 33 (1), pp. 1-13

Dworkin, R. (1989). Los derechos en serio, Barcelona: Ariel.

Dworkin, R. (1994). El dominio de la vida, Barcelona: Ariel. 
Garzón, I. (2007). La despenalización del aborto en algunos en algunos casos y bajo ciertos supuestos. Consideraciones acerca de la sentencia C-355 de 2006 de la Corte Constitucional colombiana. Revista Facultad De Derecho y Ciencias Políticas, Medellín, 36, (106), pp. 181-211.

Garzón, I. (2012). “El debate público sobre cuestiones éticas y religiosas en Colombia. Algunas lecciones habermasianas". En Tolerancia y derecho. Un análisis desde los derechos LGTBI, Medellín: Sello Editorial Universidad de Medellín, pp. 171-199.

Habermas, J. (2001). Facticidad y validez, Madrid: Editorial Trotta.

Habermas, J. (2006). Entre naturalismo y religión, Madrid: Paidós.

Habermas, J. (1999). La inclusión del otro: estudios de teoría política, Barcelona: Paidós. Habermas, J. (2000). Aclaraciones a la ética del discurso, Madrid: Editorial Trotta.

Habermas, J. (2002). El futuro de la naturaleza humana ¿Hacia una eugenesia liberal?, Barcelona: Paidós.

Habermas, J. (2009). iAy Europa!, Madrid: Editorial Trotta.

Henao, J. C. (2013). Las funciones del juez constitucional como actor de políticas públicas, Revista de Economía Institucional, 15(29), pp. 67-102.

Herrera Duran, N. (5 de octubre de 2012). Aborto: de lo moral a lo constitucional. El Espectador. Recuperado de http://www.elespectador.com/noticias/politica/ aborto-de-moral-constitucional-articulo-379639.

Lafont, C. (2007). Religion in the Public Sphere: Remarks on Habermas' Conception of Public Deliberation in Post-secular Societies, Constellations 14(2), pp. 239-259.

Lafont, C. (2009). Religion in the Public Sphere, Philosophy and Social Criticism, 35(1-2), pp. 127-150.

Letelier Wartenberg, R. (2011). La Justicia Constitucional en el pensamiento de Jürgen Habermas. En Estudios Constitucionales, Talca: Centro de Estudios Constitucionales de Chile - Universidad de Talca, 9(2), pp. 377-394.

Mejía Quintana, O. (2012). El dilema histórico de la decisión judicial. La teoría del derecho de Jürgen Habermas. Revista Panameña De Política (14) 67-103. Recuperado de http://cidempanama.org/wp-content/uploads/2013/05/ELdilema-hist $\%$ C3\%B3ricoRPP14.pdf

Rawls, J. (1996). Liberalismo Político, Bogotá: FCE.

Rawls, J. (1990). Sobre las libertades, Barcelona: Paidós.

Rummens, S. (2006). Debate: The Cooriginality of Private and Public Autonomy in Deliberative Democracy. En: Journal of Political Philosophy, 14(4), pp. 469-481. Silva Rojas, A. (2005). Pluralismo y política en las sociedades contemporáneas: el legado de la modernidad. En A. Silva Rojas, P. García Obando \& M.A. Martínez, 
María Elvira. ¿Más allá de la filosofía moderna? Un diálogo con los contemporáneos, Bucaramanga: Ediciones UIS. pp. 125-206

Walhof, D. (2013). Habermas, Same-Sex Marriage and the Problem of Religion in Public Life, Philosophy and Social Criticism, 39(3), pp. 225-242. 
